\title{
Optical Braille Blocks for Visually Impaired Elementary Education
}

\author{
Attiya Baqai ${ }^{1}$, Maria Jan ${ }^{2 a}$, Rafay Rasheed Maher ${ }^{2 b}$ \\ RECEIVED ON 13.04.2019, ACCEPTED ON 14.11.2019
}

\begin{abstract}
Learning through play has always proved its effectiveness in elementary education and has yielded prolific results. Although there are trained instructors, special schools, specific toys and facilities for Visually Impaired (VI), yet the communication between tutors and special children holds a significant gap. Also, tools in market are either too expensive or available in limited quantity in underdeveloped countries. This paper presents a cost effective solution for visually impaired children to play and learn via Braille blocks. These blocks are designed by embossed motives representing numbers, alphabets, shapes and mathematical operators with Infra-Red (IR) tags. The blocks transmit Infrared codes when come in contact with the system. The Braille Blocks System consists of a battery, optical detectors and controller which performs detection and processing of selected IR pattern. This system comprises of three different learning modules namely Words Game, Shapes Game and Math Game. These modules are further divided into several sub-game sections so that the children can learn and improve their communication and academic skills. The presence of audio feedback elevates a child's capabilities to memorize and concentrate on self-learning and spatial coordination in a fascinating way. The designed system was tested on 20 blind children in "National Special Education Complex" Karachi, Pakistan and an assessment was conducted on basis of different types of errors encountered by children. The suitability of the system was also evaluated by taking feedback from blind students through a questionnaire, proving its effectiveness with $\mathbf{7 9 \%}$ of blind children giving either good or very good feedback.
\end{abstract}

Keywords: Visually Impaired Person, Optical Braille, LED, Photo-detector, Infra-Red Tags IR-Tags, Tangible Interface Unit (TIU).

\section{INTRODUCTION}

$\mathrm{T}$ There are plenty of educational toys available in market for normal children but very limited and expensive tools are available for children with visual disabilities. Since unsighted children cannot visually recognize objects, also they are deprived of visual cues; hearing assistance and tactical information in their educational outfits can prove to be very handy aspects in their learning. These aspects can be implemented by introducing different and right methodologies of learning, which may involve games and recreational activities. For psychological progression, it is important to encourage and motivate special children to enhance their skills with help of family and friends [1-2].

Electronic Gadgets and tools in market for VI children are not only expensive but their electronic assemblies are complex too. Moreover, they are generally either educational or gaming devices. On other hand, our developed braille block system utilizes very simple electronic assembly and is quite affordable. In this research an educational system is

${ }^{1}$ Institute of Information and Communication Technologies, Mehran University of Engineering and Technology, Jamshoro, Pakistan. Email: attiya.baqai@ faculty.muet.edu.pk (Corresponding Author)

${ }^{2}$ Ministry of Defense, Karachi, Sindh, Pakistan. Email: aengr_shaikh14@yahoo.com, brafeymaher@yahoo.com This is an open access article published by Mehran University of Engineering and Technology, Jamshoro under CC BY 4.0 International License. 
created using braille blocks with simple optical coding and decoding mechanism to keep the system affordable while introducing different game modules to enhance the skills of VI children. This paper not only takes care of the children's primary age requirement i.e. class 1 to 5 but also evaluates their performance.

The paper is organized as follows. Section 2 presents related work and literature review; Section 3 discusses the system design of the Braille blocks and the maze using optical signalling. Section 4 describes the design of game modules along with their working algorithms and processing. Section 5 discusses the children performance on basis of occurrence of various types of errors. This section also discusses the suitability of the system in view of children's feedback for designed questionnaire whereas Section 6 concludes the paper.

\section{RELATED WORK}

[3] has proposed and analyzed A-J+3+6 method in comparison to conventional stylus and slate for easy learning of braille through typing. [4, 5] have developed interfaces to learn and type braille on tablet computers and smartphones. Blocks or bricks have always been an attractive toy for children for early learning. [6] uses simple wooden blocks with embossed braille letters, these blocks are not electronic so don't have any feedback. [7] incorporated one Braille cell as well as six cell device with voice feedback for blind children to practice the use of a stylus for writing in Braille. It uses an Arduino Nano microcomputer and an Aques Talk pico voice-synthesis Large-Scale Integration (LSI) to give voice feedback. There is a "Braille" switch under each hole that is used to give tactile feedback when the stylus is inserted in a hole. The device was limited to six cells and could only be used for 6 letter words. Besides the cells were fixed which could only be manipulated by inserting stylus. [8] developed an automated braille writing tutor to be used in conjunction with computer with the help of switches, microcontroller and audio feedback to replace traditional slate and stylus. The authors pointed out lack of the availability of games in education of VIimpaired children and have developed two games the animal game and hangman inspired game to motivate students for learning spellings or letter formation through braille. Tack- Tiles [9] use Lego type braille blocks in multiple languages, it supports Nemeth Braille Code for mathematics, Braille code for music notation, and computer Braille code. [10] is light aid from Philips and Perkins Products in form of colourful display to teach children with low vision, cognitive and multiple disabilities. [11] has proposed electronic braille blocks by combining technology with conventionally used blocks with the help of Near Field communication (NFC) tags beneath the blocks in order for their automatic recognition. The braille blocks are in forms of alphabets. The tags once acquired after placement on the tray are processed by a computer to be recognized. [12] describes a P-Cube designed to teach VI children basic programming concepts like sequential and line trace programs with the help of blocks to be placed on a maze. The blocks are equipped with RFID Tags whereas the mat consists of 30 holes and RFID readers. $[13,14]$ use E Blocks to teach programming concepts to young children in which each block has a single chip microcomputer, an infrared transmitter and receiver module, a cell battery module, a wireless module, and an LED. Its working is based upon transmission of identity code to wireless box which is connected to PC through USB port. [15] has developed a Tangible user interface to teach tactual shape perception and spatial awareness for VI children utilizing computer vision-based system to track tagged 3D printed geometric shapes. AutoMathic [16, 17] is a system for teaching arithmetic and beginning algebra using Brailleembossed blocks with barcodes affixed to their bases. The child can pick up a block, pass it over a barcode scanner attached to a computer and then place it within a grid on a touchpad device. The Braille embossed blocks are stored in a simple plastic "jig" that comes from a commercial version of the Sudoku game. The test grid contains 9 rows by 9 columns. [18] is a smartphone based navigation system that uses Google Directions Application Program Interface (API). This system guides visually impaired pedestrians with the right path to reach the destination, with the assistance of a vibration belt. Table 1 summarizes the comparison to the state of the art. 


\begin{tabular}{|c|c|c|c|}
\hline \multicolumn{4}{|c|}{ Table 1: Comparison to the State-of-the-art } \\
\hline $\begin{array}{l}\text { Ref. } \\
\text { No. }\end{array}$ & Related Work & Limitation & Improvement In Our System \\
\hline$[1]$ & $\begin{array}{ll}\begin{array}{l}\text { Interactive system for } \\
\text { math learning }\end{array} & \\
\end{array}$ & $\begin{array}{ll} & \text { Use of Computer } \\
\text { makes it expensive }\end{array}$ & - Embedded solution \\
\hline$[2]$ & $\begin{array}{l}\text { Device to provide } \\
\text { assistance in recognizing } \\
\text { letters and words in } \\
\text { braille for basic reading }\end{array}$ & $\begin{array}{ll}- & \text { Heavy weight and } \\
\text { Costly }\end{array}$ & $\begin{array}{l}\text { (microcontroller) makes it } \\
\text { affordable/ cheap } \\
\text { - Light Weight }\end{array}$ \\
\hline [7] & $\begin{array}{l}\text { Device using both voice } \\
\text { feedback and tactile sense } \\
\text { to help blind use Braille } \\
\text { stylus }\end{array}$ & $\begin{array}{ll}- & \text { Big size } \\
- & \text { Fast speed of speaking } \\
- & \text { Low volume }\end{array}$ & $\begin{array}{l}\text { - } \text { Compact size } \\
\text { - Standalone; does not use }\end{array}$ \\
\hline [15] & $\begin{array}{l}\text { User interface software } \\
\text { solution printing 3D } \\
\text { objects via 3D printer to } \\
\text { distinguish objects }\end{array}$ & $\begin{array}{l}\text { Pricey due to } \\
\text { utilization of 3D } \\
\text { printer }\end{array}$ & $\begin{array}{l}\text { computer or PC } \\
\text { - Text to music/ voice } \\
\text { feedback to help visually }\end{array}$ \\
\hline [18] & $\begin{array}{l}\text { User friendly navigation } \\
\text { system using keyboard to } \\
\text { input and let the blind } \\
\text { person reach end } \\
\text { destination }\end{array}$ & $\begin{array}{ll}- & \text { flaws in Google } \\
\text { - } & \text { directions API } \\
\text { high installation cost } \\
\text { - } & \text { unable to identify } \\
\text { current user location }\end{array}$ & $\begin{array}{l}\text { 1mpaired perform tasks } \\
\text { - Software implementation } \\
\text { for Words/ shapes/ Maths } \\
\text { Games }\end{array}$ \\
\hline
\end{tabular}

Our prototype tries to compensate between the maximum features it can offer within the cheapest range possible as it does not require computer or smart phone. It only uses microcontroller for processing purpose rather than a microcontroller within each block which can render the system expensive. The IR tags for each braille block are made through simple and cheap LEDs and photo detectors. No specific or expensive reader is required to decode the IR Tags.

\section{SYSTEM DESIGN AND ARCHITECTURE}

The Braille Blocks System comprises of four major components: Braille blocks, multiplexer, microcontroller unit and speaker/ headphone. Braille blocks used in this system are of two types: Transmitter (Tx) Blocks and Receiver (Rx) blocks, shown in Fig. 1. Transmitter blocks are of six major categories: Alphabet blocks, Shapes blocks, Space block, Sign blocks, Mathematical Operator blocks and Numbers blocks.

The Front view of Tx Blocks consist of embossed motives/ shapes (different braille patterns), indicating the type of alphabet/ number or geometrical shape respectively. There is an embossed plate (non- conducting), on top of each block, which helps VI children to indicate orientation of Tx block.

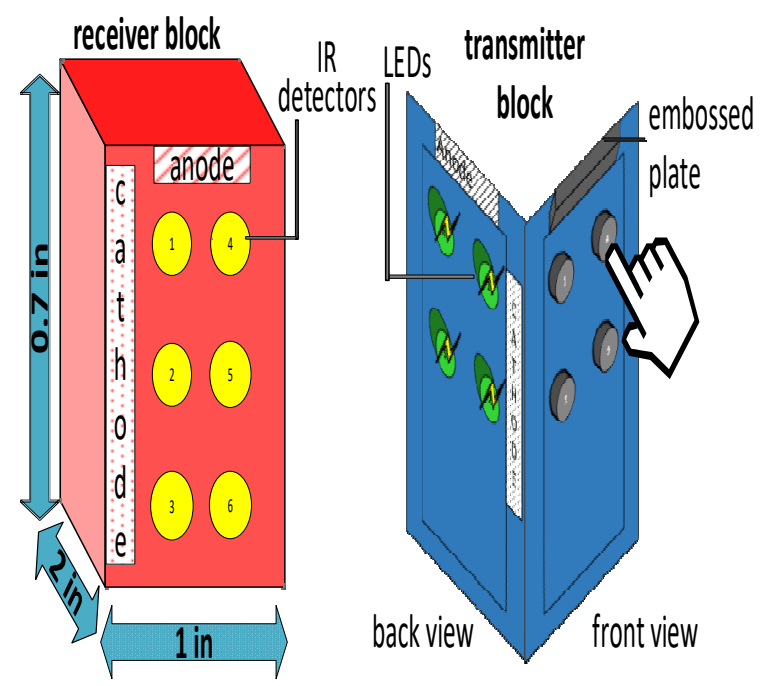

Fig. 1: RX and TX Braille Blocks.

The Back view of Tx block consists of same number of light emitting diodes (LEDs) as there are embossed braille motives. For shapes blocks, number of LEDs depend on starting letter of shape's name e.g. Square shape block has starting letter ' $\mathrm{S}$ ', braille pattern for 
' $S$ ' letter has 3 dots hence three (03) LEDs for this shape. Children analyze characters by touching motives/shapes and their position and identify desired block. Each Receiver block consists of six IR detectors ( 0.2 inches diameter each), placed at a distance of 0.1 inch from other IR detectors as shown in Fig. 1. Overall dimensions of Braille Blocks System are (Length $\mathrm{x}$ Width $\mathrm{x}$ Height) $16 \times 5 \times 2$ inches. Two conductive plates i.e. anode and cathode are placed on Rx block so that electrical supply may be provided to Tx block's LEDs. When a child places Tx block over Rx block, IR detectors on Rx block detect light signals generated by Tx block's LEDs.

The system layout is shown in Fig. 2 and the individual components are described as follows:

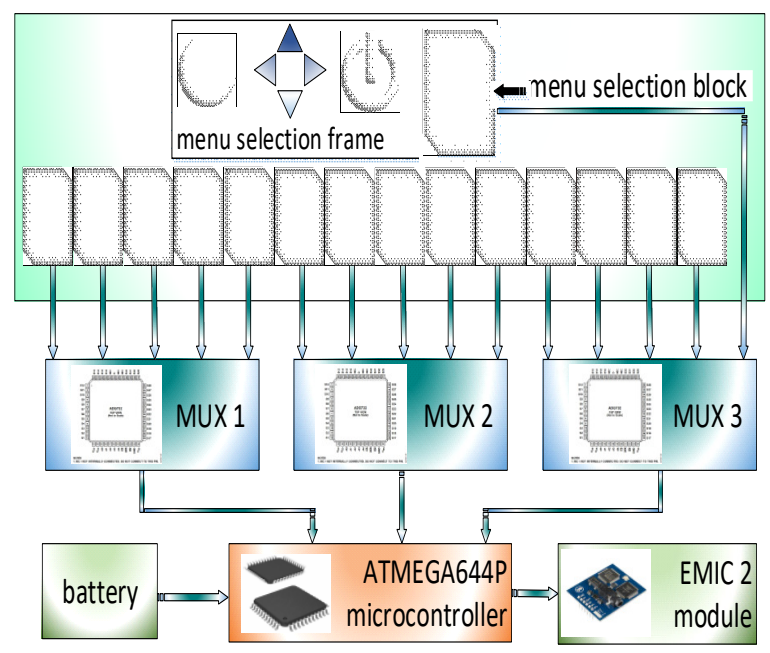

Fig. 2: Conceptual diagram and system layout.

Menu selection frame consists of a Menu selection block, an audio jack, back button, forward button, main menu button, exit and power on/off buttons as shown in Fig. 2. The Menu selection block is used for selection of different learning modules.

This system has fourteen (14) receivers. Each receiver block has six outputs, connected to a multiplexer.

The ADG732 is a 32-channel Multiplexer (MUX). At one instance, only one input among thirty two (32) inputs is fed to the output of MUX. Here, three (03) multiplexers are used to incorporate ninety (90) outputs of fourteen (14) Receiver blocks and a Menu selection block.
The Atmel ATmega644P is an 8-bit Microcontroller (MCU) based on AVR enhanced RISC architecture. MCU is the core of this system as it interfaces all the components. Also, learning modules software lies within this Unit. A $5 \mathrm{~V}$ battery provides power to this system.

Emic 2 Text-to-Speech Module 30016 is utilized in this design. It is a multi-language voice synthesizer which converts a text stream into audio output. Emic 2 is interfaced with MCU via serial protocol (TTLlevel interface). MCU sends desired input command to Emic 2 module and audio output can be heard from speakers via an audio jack. This module incorporates nine built-in voice styles of male, female, and child.

\section{WORKING ALGORITHM}

The Braille Blocks System consists of a MCU, which is programmed to follow gaming instructions so that a child can learn and play different modules. The child accomplishes gaming modules by listening instructions on audio feedback. The overall layout for the gaming modules incorporated in this research is illustrated in Fig.3.

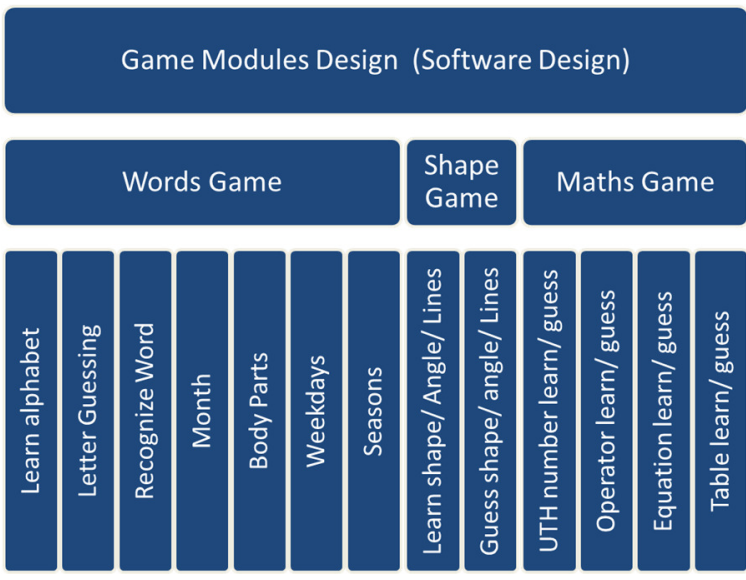

Fig.3: Game Modules incorporated in software for optical braille blocks.

The device works in a sequential manner explained as follows

- Start the device on power up

- Music and welcome message will be played on speaker for child to begin playing. 
- Menu instructions will be played on speaker for child to choose an option from the following designed game modules.

i. Alphabets/ Words

ii. Shapes

iii. Numbers/ Mathematical Operations/ Tables

The child has to place a number block of 1,2 or 3 in the right most slot which is coded in main program to detect the selected option by the child. The MCU detects particular block using IR detectors attached at base of receiver block through multiplexer and pronounces the character on speaker. Child chooses either Words Game, Shapes Game or Maths Game and starts learning as explained in the subsequent subsections.

\subsection{Module 1 - Words Game}

Words Game consists of subsequent categories: Learn alphabet game, letter guessing game, recognize word game, month game, body parts game, week-days game and seasons' game.

i. If the child selects option 1 i.e. for alphabets or words, a message is played on speakers to place any alphabet block from available letters on the tray.

ii. The microcontroller will detect the block using IR tag attached at the base of the block using LEDs and pronounce the letter to the child so that he can learn the alphabet and memorize it.

iii. The program asks the child to remove the block and place the new one in the same place if he wants to continue otherwise press the back/ forward button to go in the previous/ next step or press exit button to end the game.

iv. If the child selects to move forward the next step after learning 26 letters in previous phase the child is then asked 5 random letters to place on the tray one by one by placing and removing from the right most position.

v. If he places a correct alphabet music/ clap/ or encouraging audio is played on the speakers, otherwise the 'try again' audio is played on the speakers. vi. The next step is for guessing the spelling of word played by audio. The child has to place the blocks in correct order to guess the spelling. If the guess is correct the child is encouraged otherwise motivated to try again through audio.

vii. In the same way the child is first trained with vowels, body part names, senses names, weekday's names, month's names, season names and then asked the questions with a story line to test child's memory and understanding of the concepts in a playful manner through audio.

viii. The child is asked at the end of this module to return to main menu or to move back/forward to the previous or next module or exit the game.

\subsection{Module 2 - Shapes Game}

Shapes Game incorporates "Learn Shapes Game" and "Shapes Guessing game" the same way as used in words learning and guessing games. Only difference being of the embossed shapes instead of letters. Similarly, the child is trained about Angles and Lines with the help of embossed lines and angles on blocks. The encoding patterns for the shapes, angles and lines programmed in the MCU are depicted in Table 2.

i. In this module the child is asked to place a random block from the available basic shapes as listed in Table 2 on the tray to listen, learn and memorize the shape through audio feedback. Each shape is assigned a letter which is designed as an IR Tag beneath the Block to be transmitted to the optical maze.

ii. The child is now asked to remove the blocks and place only the spoken shape on the tray.

iii. If the child places a correct shape music/ clap/ or encouraging audio is played on the speakers, otherwise 'try again' audio is played on the speakers.

iv. In the same way the child is trained about angles/lines with the help of embossed lines and angles on the blocks.

v. The child is asked at the end of this module to return to main menu or to move back/forward to the previous or next module or exist the game. 


\subsection{Module 3 - Maths Game}

Maths Game incorporates "UTH" (Unit-TenHundred) and "Operators" $(+,-, \times, \div,=)$ learning and guessing games, same methodology is used as employed in previous games. Difference is that numbers and operators are used instead of letters or shapes. In "Equation game" child is asked to place numbers (maximum 2 digits) and operator block to form a simple equation and answers the result so child can learn performing addition, subtraction, multiplication and division. In "Learning Tables" (2 to 20), game pronounces each table's equations and child is asked to enter them. However, in "Tables guessing" game, child is asked to enter equations for a table. The encoding patterns for numbers, operators and equations programmed in MCU are depicted in Tables $3-5$.

Table 2: Encoding/ decoding patterns for Module 2 in designed optical braille blocks system

\begin{tabular}{|c|l|c|l|c|c|c|}
\hline \multicolumn{7}{|c|}{ Table 2: Encoding/ decoding patterns for Module 2 in designed optical braille blocks system } \\
\hline S.No. & \multicolumn{1}{|c|}{ Shapes } & Encoding Pattern & Angles & $\begin{array}{c}\text { Encoding } \\
\text { Pattern }\end{array}$ & Lines & $\begin{array}{c}\text { Encoding } \\
\text { Pattern }\end{array}$ \\
\hline 1 & square & $\mathrm{s}$ & right & $\mathrm{i}$ & vertical & $\mathrm{v}$ \\
\hline 2 & rectangle & $\mathrm{r}$ & acute & $\mathrm{a}$ & horizontal & $\mathrm{n}$ \\
\hline 3 & triangle & $\mathrm{t}$ & obtuse & $\mathrm{b}$ & parallel & 1 \\
\hline 4 & circle & $\mathrm{c}$ & & & perpendicular & $\mathrm{u}$ \\
\hline 5 & hexagon & $\mathrm{h}$ & & & & \\
\hline 6 & pentagon & $\mathrm{p}$ & & & & \\
\hline 7 & eclipse & $\mathrm{e}$ & & & & \\
\hline 8 & oval & $\mathrm{o}$ & & & & \\
\hline 9 & octagon & $\mathrm{g}$ & & & & \\
\hline 10 & diamon & $\mathrm{d}$ & & & & \\
\hline 11 & star & $\mathrm{z}$ & & & & \\
\hline 12 & heart & $\mathrm{x}$ & & & & \\
\hline
\end{tabular}

\begin{tabular}{|c|c|c|c|c|c|c|c|c|c|c|}
\hline \multicolumn{11}{|c|}{ Table. 3: Encoding/ decoding patterns for Braille Numbers } \\
\hline : & 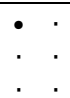 & $\because$ & 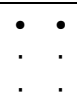 & $\because$ & $\because$ & $\because$ & $\because$ & $\because$ & & $\therefore$ \\
\hline \# & 1 & 2 & 3 & 4 & 5 & 6 & 7 & 8 & 9 & 0 \\
\hline
\end{tabular}

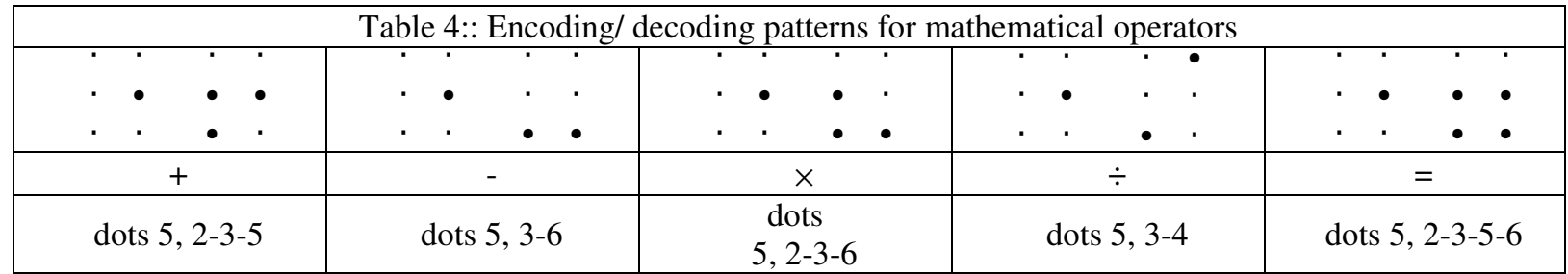

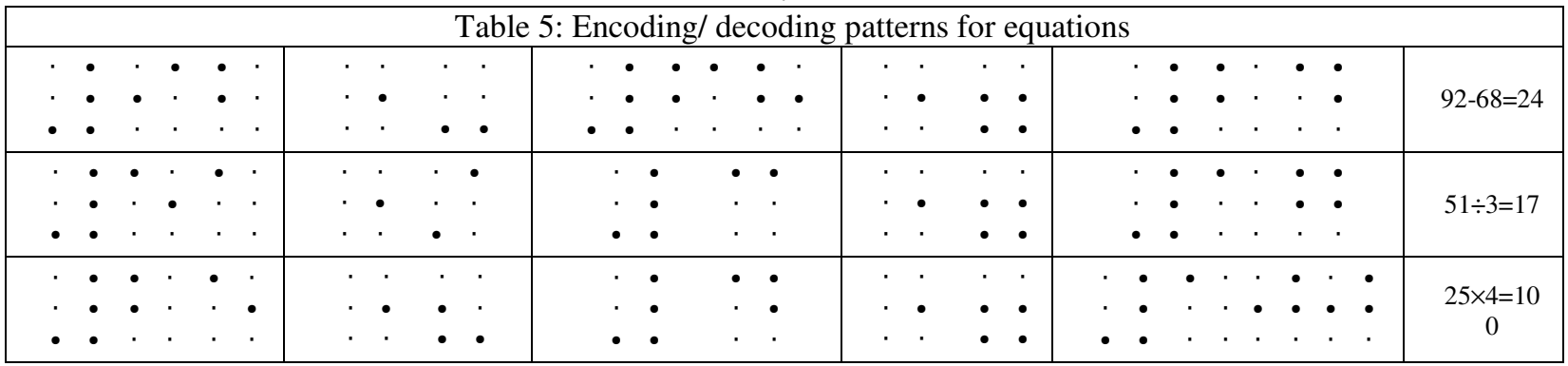

The game in this module proceeds as follows:

The child is first asked to place random blocks from the available numbers upto three digits for unit only unit \& ten's or unit-ten- hundred place digit blocks on the tray to listen, learn and memorize the numbers through audio feedback. 
i. The program asks the child to remove the blocks and place the new ones in the same place if he wants to continue otherwise press the back/ forward button to go in the previous/ next step or press exit button to end the game.

ii. If the child selects to move forward after learning the numbers in previous phase the child is now asked 5 random numbers to place on the tray one by one by placing and removing from the units, ten's \& and hundred places.

iii. The Microcontroller will check each block after it has been placed on the tray at individual digit place to give the feedback accordingly and instantly and in the end as well when all the digits of a number are placed at their respective digit places.

iv. If the child places correct number blocks music/ clap/ or encouraging audio is played on the speakers, otherwise the 'try again' audio is played on the speakers.

v. The child is asked to move back/forward to the previous or next step in the number module or exit the game.

vi. The next step is to learn the simple mathematical operations and their braille representation using blocks. The child is first asked to place random block from the available five basic operations i.e. '+', '-‘, ' $\times$ ', ' $\div$ ', '=' on the tray to listen, learn and memorize them through audio feedback.

vii. The audio message then asks the child to place number (2 digit maximum range) and operator blocks to form a simple equation and speak out the result so that the child can learn its mechanism for performing addition, subtraction, multiplication, division and calculation of these operators.

viii. The audio then asks the child if he wants to learn more or want to play quiz according to the activity learned in previous step. The child then presses the back/ forward button to go in the previous/ next step or press exit button to end the game.

ix. In this step the audio asks the child to solve random equations and place appropriate blocks on the tray to write and calculate the answer.

x. The Microcontroller will check each block after it has been placed on the tray at individual digit or operator place (including number sign) to give the feedback accordingly and instantly; and in the end as well when all the digits of a number are placed at their respective digit places.

xi. If the child places correct blocks for the result a music/ clap/ or encouraging audio is played on the speakers, otherwise the 'try again' audio is played on the speakers.

xii. The audio then asks the child if he wants to play more or move to the next step for learning multiplication table. The child then presses the back/ forward button to go in the previous/ next step or press exit button to end the game.

xiii. In learning multiplication table mode the child is asked to place the number whose table he wants to learn. The child then follows step by step audio instruction to place blocks for a product of a table from 1 to 10 along with the result so that a child can learn it.

xiv. The program then takes child's input to continue learning or play quiz and proceed to the next step.

xv. The next step is for asking the student to solve a random table quiz, i.e. the child should place blocks of the asked table in sequence and then random products from the same multiplication table are asked.

xvi. If the child places correct blocks for the result a music/ clap/ or encouraging audio is played on the speakers, otherwise the 'try again' audio is played on the speakers.

xvii. The audio then asks the child if he wants to play more. The child then presses the back or exit button to end the game.

xviii. Throughout the session the student can go into the main menu at any time by pressing the restart button.

xix. In each game, if block is placed correctly then speaker pronounces and plays message "correct block/well-done", else plays "wrong block/ try again".

\section{RESULTS AND DISCUSSION}

The experiments are carried out on twenty (20) blind children of Class 1 to 5 individually. An assessment is conducted on basis of errors encountered by children. Each child's learning and practicing pace is evaluated for modules and questions attempted by him. Error percentage is calculated by errors encountered from questions attempted. The data for analysis is gathered 
with help of programmed microcontroller, instructor's observation and child's feedback.

Fig. 4 indicates that highest total error achieved was $40 \%$. It is observed that percentage of total errors in range of $20-40 \%$ is mainly due to wrong answers by young children (Average $($ Avg) $=8.5 \&$ Standard Deviation $(S . D)=5.6$ ); elder children who already had concepts, recalled spellings more efficiently. The children had difficulty initially in learning new concepts about words, numbers and shapes; but with increased practice time, there was great improvement in their performance. Percentage of errors due to omission of space block ( $\mathrm{Avg}=2 \& \mathrm{~S} . \mathrm{D}=1.2)$ as well as start block ( $\mathrm{Avg}=3.55 \& \mathrm{~S} . \mathrm{D}=1.82)$ is low; it shows that embossed plates provided great help. There were $10 \%$ errors for only one child due to comprehending audio. However, performance greatly improved due to customizable speed and volume of sound. Percentage of errors due to skipping of letter/ number blocks is also low $(\operatorname{Avg}=4 \&$ S.D $=2.66)$.

It can be observed from Fig. 5 that most of the students found mechanism of IR Braille Block System to be easy to learn as it is based on self-pace and not the time constraints. As the maze and the blocks are of suitable dimensions with proper placing of the menu selection buttons, most of the students find it convenient to handle and operate. The dimensions of the block are easy to grab for the little hands. The spacing between the blocks is quite adequate but the student's feedback indicated that it can be improved if they have some more room to pick and place the blocks upon the maze easily. The spacing and height between the embossed dots was quite comfortable for the students, younger children mostly liked greater heights, more spacing with greater radius of embossed dots. The blocks are made of fine plastic, some students prefer wooden blocks whereas some prefer plastic due to possibility of splinter in wood and familiarity with lego type blocks. As the major playing is based upon audio feedback, special emphasis is paid on the adjustment of pitch, frequency and volume of audio, the feedback indicated that different students have different preferences and hence same setting cannot be applied for all the students. The audio is adjusted through customizable settings before starting the game according to student's likeness and comfort level to comprehend it easily. It is witnessed through the questionnaire that the students liked Module 2 the most as it was easy and interesting to learn about geometrical concepts without memorizing the dot number and placements whereas they found difficulty in learning higher level games in maths in accordance to their age. In spite of facing some difficulty the students quickly learnt the concepts in comparison to the conventional methods used in schools. The students like the idea of providing multiplication tables as a game; providing some means to balance the abundance of multiplication table booklets and Mobile apps availablity for their sighted peers. The improvement in skills due to IR Braille block system games was quite appreciating as most of the students showed considerate progress.

Fig. 6 indicates that 79\% children gave either good or very good feedback for most of the questions, which is quite encouraging for suitability of our system.

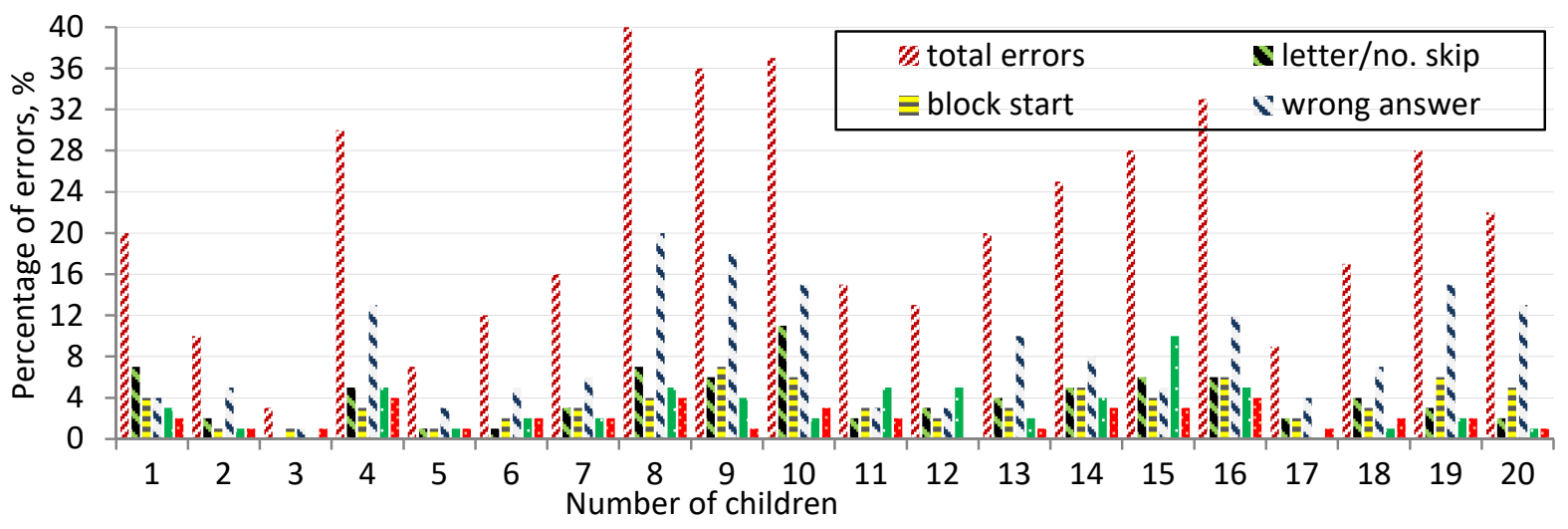

Fig. 4: Performance evaluation based on Errors 


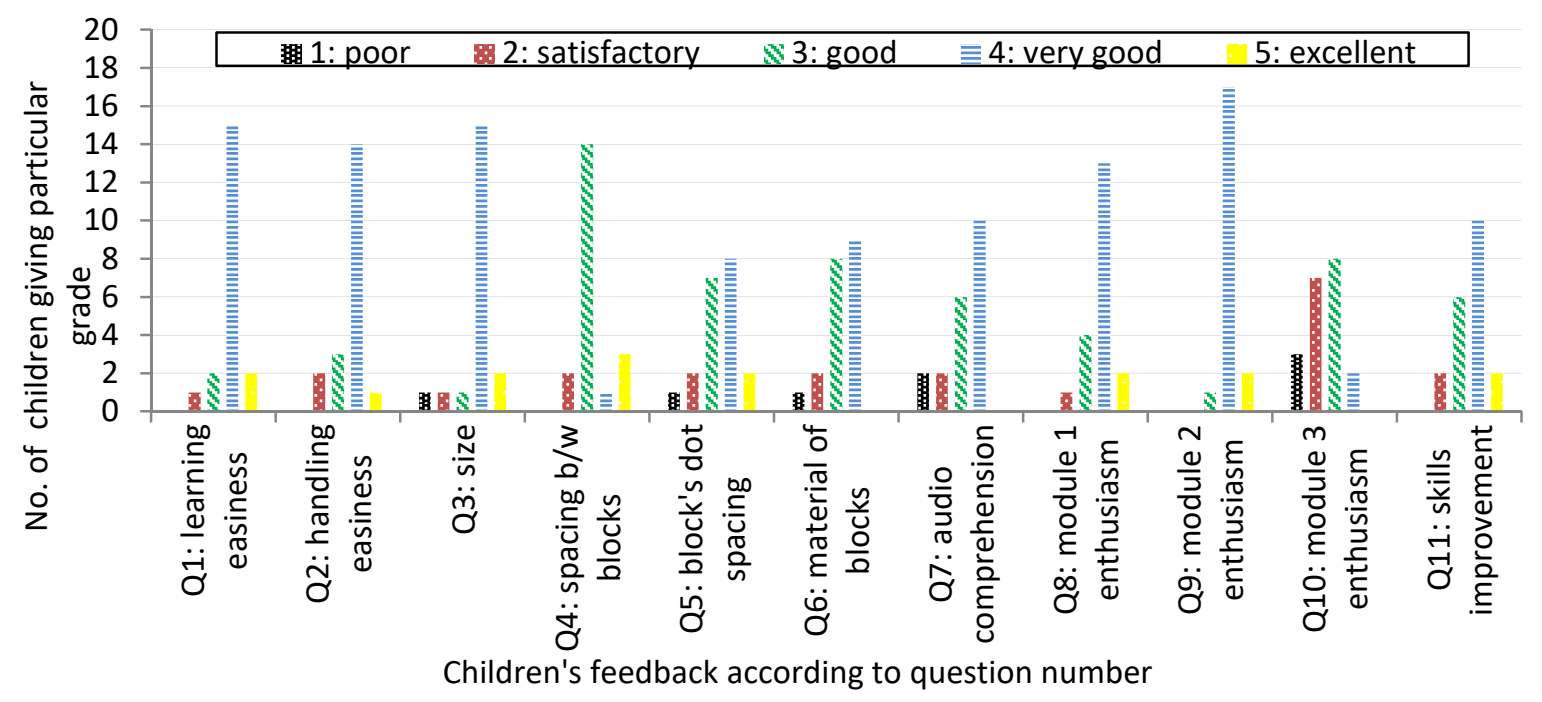

Fig. 5: Children's feedback about IR Braille block system

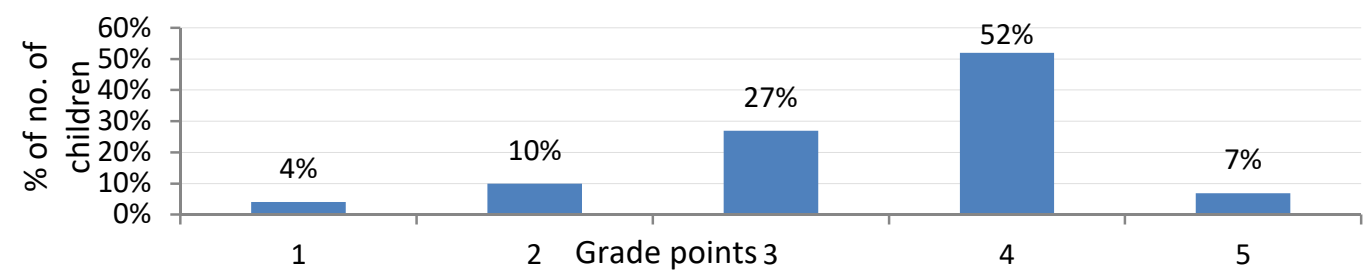

Fig. 6: Children overall feedback ratings to the questionnaire

\section{CONCLUSION}

The designed system was tested on twenty (20) blind children from Grade 1 to 5 in "National Special Education Complex" Karachi, Pakistan. Children's performance results and feedback while testing indicate that, children enjoyed learning different gaming modules. The supervisors at complex also appreciated our efforts to build up a user-friendly system that helped blind children enhance and groom their communication skills via braille patterns. The overall cost of our system is approximately 75 USD, which reflects reasonable amount for such needful purpose. Future extensions can also be made into Braille Blocks System by extending its prospect to a square shaped Maze for creating gaming modules such as two-dimensional (2D) word puzzles, scrabble, etc.

\section{ACKNOWLEDGMENTS}

This project was carried out in Institute of Information and Communication Technologies (IICT), Mehran University of Engineering and Technology Pakistan. The authors are grateful to the Department of Electronic Engineering and Directorate of IICT of MUET for the technical support respectively. We are also thankful to "National Special Education Complex", Karachi for their utmost support and cooperation.

\section{REFERENCES}

[1] Pires A.C., Marichal S., Gonzalez-Perilli F., Bakala E., Fleischer B., Sansone G., Guerreiro T., A Tangible Math Game for Visually Impaired Children", The Proceedings of the $21^{\text {st }}$ International ACS Conference on Computers and Accessibility, Pittsburgh, P.A., U.S.A., pp. 660-672, October 28 - 30, 2019,

[2] Lopez R.M., Pinder S.D., Davies T.C., "Matulo, Magbasa, Maglaro: Learning to 
Read Braille through Play", Assistive Technology, Vol. 3, pp. 1-9, 2019.

[3] Kway E. H., Mohd N., and Abd R., "Slate and Stylus: An Alternative Tool for Braille Writing", Journal of Procedia - Social and Behavioral Sciences, Vol. 7, No. 2, pp. 326335, 2010.

[4] Matsuda Y. and Isomura T., "Teaching Interface of Finger Braille Teaching System Using Tablet Computers", Proceedings of the Sixth International Conference on Intelligent Human-Machine Systems and Cybernetics, pp. 42-45, 2014.

[5] Ushida K., Sekine Y., and Hasegawa S., "IPPITSU: A one-stroke text entry method for touch panels using Braille system", Proceedings of the 3rd IEEE Global Conference on Consumer Electronics (GCCE), Vol. 3, pp. 374-375, 2014.

[6] "Braille Alphabet Blocks Toy." [Online]. Available:

https://www.littlesaplingtoys.com/collection s/wood-blocks/products/braille-alphabet-

blocks-tactile-wooden-letters-

toy? variant $=1316466332$. [Last Accessed on

February 20, 2019].

[7] Aizawa F., Watanabe T., "A braille writing training device with voice feedback," Proceedings of the 16th International ACM Conference on Computers and Accessibility, pp. 243-244, 2014.

[8] Rahman M.K., Sanghvi D+S., El-Moughny N., "Enhancing an Automated Braille Writing Tutor", Proceedings of the IEEE/RSJ International Conference on Intelligent Robots and Systems, pp. 2327-2333, 2009.

[9] "Track Tiles Braille System", [Online], Available: http://www.tack-tiles.com/, [Last Accessed on February 20, 2019].

[10] "Perkins Solution", [Online]. Available: http://www.perkins.org/solutions/featuredproducts/lightaide, [Last Accessed on February 20, 2019].

[11] Jafri R., "Electronic Braille Blocks: A Tangible Interface Based Application for Teaching Braille Letter Recognition to Very Young Blind Children", Lecture Notes on Computer Science, including Sun Series
Lecture Notes on Artificial Intelligence, Lecture Notes on Bioinformatics, Vol. 8548, LNCS No. 2, pp. 551-558, 2014.

[12] Kakehashi S., Motoyoshi T., Koyanagi K., Ohshima T., Kawakami H., "P-Cube Block Type Programming Tool for Visual Impairments", Proceedings of the Technological Applications of Artificial Intelligence, pp. 294-299, 2013.

[13] Wang D., Zhang Y., Gu T., He L., Wang H., "E-Block", Proceedings of the ACM Symposium on User Interface Software Technology, p. 71, 2012.

[14] Wang D., Zhang Y., Chen S., "E-Block: A Tangible Programming Tool with Graphical Block", Mathematical Problems in Engineering, Vol. 2013, 2013.

[15] Jafri R. Aljuhani A.M., Ali S.A., "A Tangible Interface Based Application for Teaching Tactual Shape Perception and Spatial Awareness Sub-Concepts to Visually Impaired Children", Procedia Manufacturing, Vol. 3, pp. 5562-5569, 2015.

[16] Karshmer A.I., Farsi D., "Manipulatives in the History of Teaching: Fast Forward to Automatic Blocks for the Blind", Computers Helping People with Special Needs, Vol. 5105, LNCS Berlin, Heidelberg, Springer, pp. 915 - 918, 2008.

[17] Breiter Y., Karshmer A., Karshmer J., AutOmathic Blocks Usability Testing Phase One", Lectures Notes in Computer Science (Including subseries Lecture Notes in Artificial Intelligence and Lecture Notes in Bioinformatics), Vol. 7382, LCSN No. Part I, pp. 191-195, 2012.

[18] Memon S.F., Memon M.A., Zardari S., Nizamani S., Blind's Eye: Employing Google Directions API for Outdoor Navigation of Visually Impaired Pedestraians", Mehran University Research Journal of Engineering and Technology, Vol. 36, No.3, pp. 693-706, 2017. 